\title{
Intestinal Obstruction Caused by a Fruit Seed: A Rare Case Without Gastrointestinal Disease
}

Takuma Iwai $^{1}$, Hiroshi Makino ${ }^{2}$, Tadashi Yokoyama ${ }^{2}$, Hiroshi Maruyama ${ }^{2}$, Atsushi Hirakata ${ }^{2}$, Toshimitsu Miyasaka ${ }^{2}$, Hiroshi Yoshida ${ }^{2}$

1. Surgery, Nippon Medical School, Tokyo, JPN 2. Oncology, Nippon Medical School, Tokyo, JPN

Corresponding author: Takuma Iwai, takumaiwai@nms.ac.jp

\section{Abstract}

We report here a rare case of intestinal obstruction caused by a peach seed. A 15 -year-old boy was admitted to our hospital because of abdominal pain and vomiting. The patient had no history of previous gastrointestinal surgery and his medical comorbidity was autism. A computed tomography (CT) scan showed an obstruction of the ileum by a foreign body. Surgical treatment was successfully performed, and we found a peach seed in the ileum. He was discharged eight days after the operation without postoperative complications. Intestinal obstruction caused by plant seeds without gastrointestinal disease is rare.

Categories: Gastroenterology

Keywords: sbo, intestinal obstruction, foreign body, seed

\section{Introduction}

Intestinal obstruction is a common disease that is encountered in surgical practice. Intestinal obstructions are often induced by adhesion, hernia, neoplasm, and inflammation, but intestinal obstruction due to feeding is rare [1]. Furthermore, plant seeds that pass through the pylorus do not induce intestinal obstruction because swallowed seeds are often small and ovoid shaped [2-3]. Therefore, in most cases of intestinal obstruction caused by plant seeds, the patients have gastrointestinal disease such as a malignant tumor and postoperative adhesion.

We describe a patient without gastrointestinal disease in whom a peach seed induced small bowel obstruction. The seed was successfully removed with surgical treatment.

\section{Case Presentation}

A 15-year-old boy was admitted to Nippon Medical School Tama Nagayama Hospital because of appetite loss, vomiting, and abdominal pain persisting for approximately seven days. The patient had no history of previous gastrointestinal surgery and his medical comorbidity was autism. His vital parameters were normal and his general physical examination results were unremarkable. An abdominal examination showed distention and mild generalized tenderness without signs of peritonitis. Laboratory studies showed a mild

Received 08/30/2018

Review began 11/14/2018 Review ended 12/20/2018 Published 12/21/2018

๑) Copyright 2018

Iwai et al. This is an open access article distributed under the terms of the Creative Commons Attribution License CC-BY 3.0., which permits unrestricted use, distribution, and reproduction in any medium, provided the original author and source are credited.

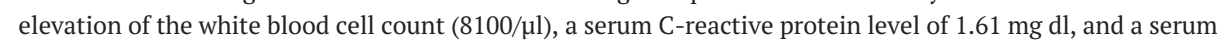
total bilirubin level of $1.9 \mathrm{mg} / \mathrm{dl}$ (Table 1 ). 


\section{Cureus}

\begin{tabular}{|c|c|c|c|c|c|}
\hline & \multicolumn{4}{|c|}{ Laboratory data on admission } & \multirow[b]{2}{*}{ IU/I } \\
\hline WBC & 8100 & /ul & AST & 22 & \\
\hline RBC & $556 \times 10^{4}$ & /ul & ALT & 14 & $\mathrm{IU} / \mathrm{I}$ \\
\hline $\mathrm{Hb}$ & 16.7 & $g / d l$ & LDH & 198 & IU/I \\
\hline $\mathrm{Ht}$ & 43.6 & $\%$ & ALP & 167 & IU/I \\
\hline \multirow[t]{4}{*}{ PIt } & 26.3 & /ul & yGTP & 13 & $\mathrm{IU} / \mathrm{I}$ \\
\hline & & & AMY & 53 & IU/I \\
\hline & & & T-bil & 1.9 & $\mathrm{mg} / \mathrm{dl}$ \\
\hline & & & TP & 7.5 & g/dl \\
\hline PT & 59.5 & $\%$ & Alb & 4.8 & g/dl \\
\hline \multirow[t]{6}{*}{ APTT } & 28.4 & sec & BUN & 17.2 & $\mathrm{mg} / \mathrm{dl}$ \\
\hline & & & Cre & 0.69 & $\mathrm{mg} / \mathrm{dl}$ \\
\hline & & & $\mathrm{Na}$ & 133 & $\mathrm{mEq} / \mathrm{l}$ \\
\hline & & & $\mathrm{K}$ & 4.1 & $\mathrm{mEq} / \mathrm{l}$ \\
\hline & & & $\mathrm{Cl}$ & 92 & $\mathrm{mEq} / \mathrm{l}$ \\
\hline & & & CRP & 1.61 & $\mathrm{mg} / \mathrm{ml}$ \\
\hline
\end{tabular}

\section{TABLE 1: Laboratory data on admission}

White blood cell (WBC), red blood cell (RBC), Hemoglobin (Hb), platelet (PIt), prothrombin time (PT), activated partial thromboplastin time (APTT), aspartic aminotransferase (AST), alanine transaminase (ALT), lactate dehydrogenase (LDH), alkaline phosphatase(ALP), $v$-glutamyltransferase (yGTP), amylase (AMY), total-bilirubin (T-bil), total protein (TP), albumin (Alb), blood urea nitrogen (BUN), creatinine (Cre), C-reactive protein (CRP)

An abdominal X-ray demonstrated dilatation and a stair-step pattern in the small intestine (Figure 1). 


\section{Cureus}

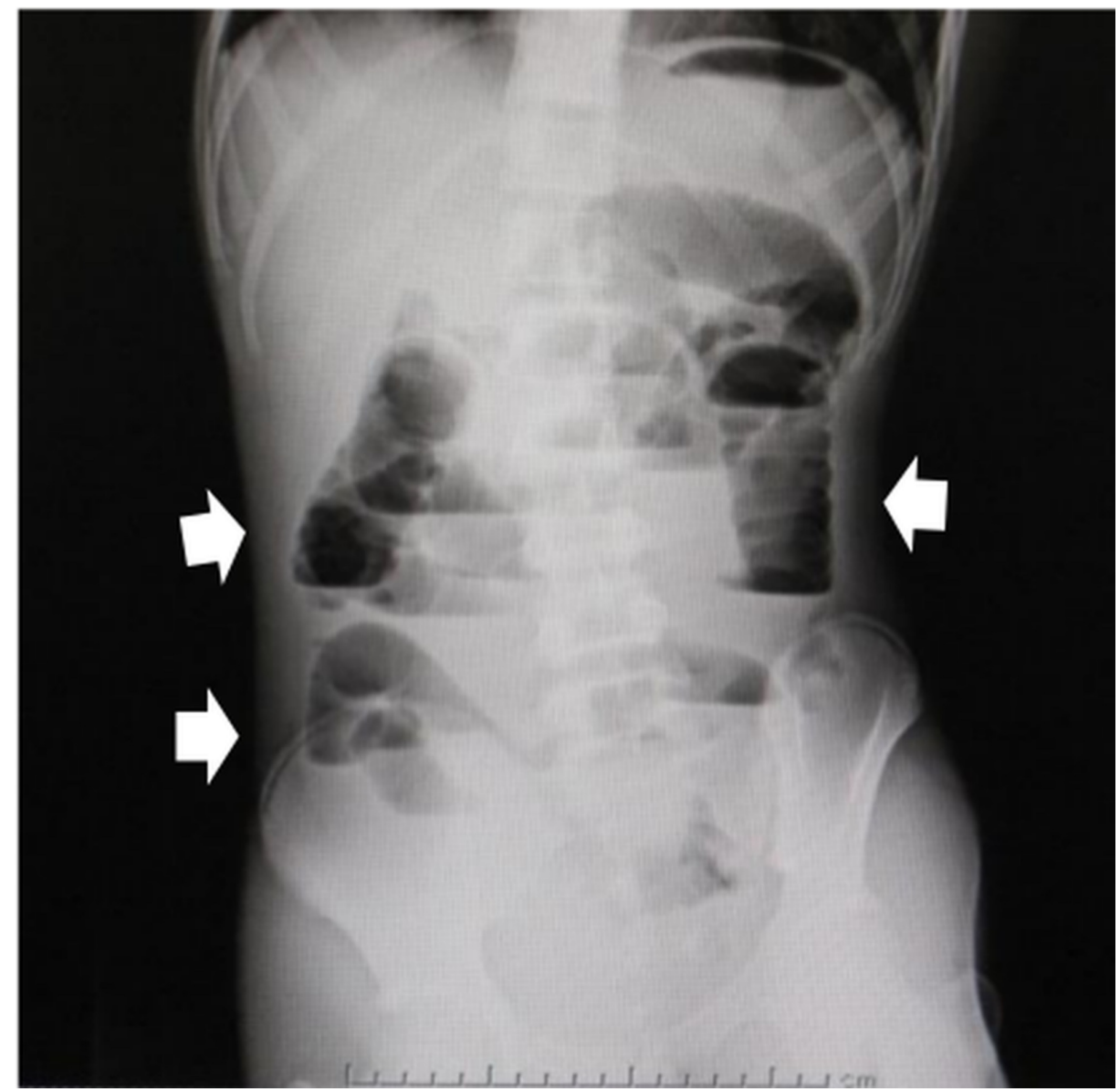

FIGURE 1: Abdominal X-ray

Plain radiography shows dilatation and a stair-step pattern of the small intestine.

Computed tomography (CT) suggested a foreign body in the ileum with proximal small bowel dilatation. The object showed high-density outside and iso-density inside. The shape of the object was oval and $30 \mathrm{~mm}$ in diameter. The 3D construction image from the CT images showed a clearer shape of the object (Figure 2).

a

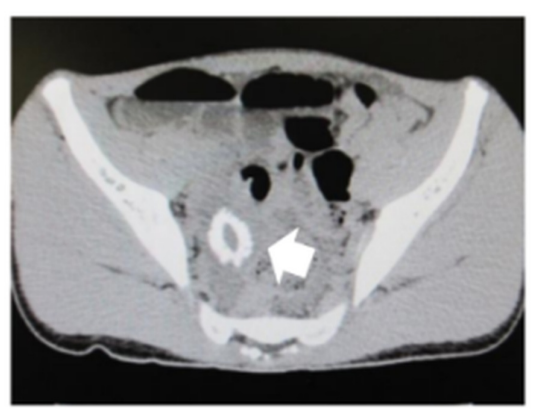

$\mathrm{b}$

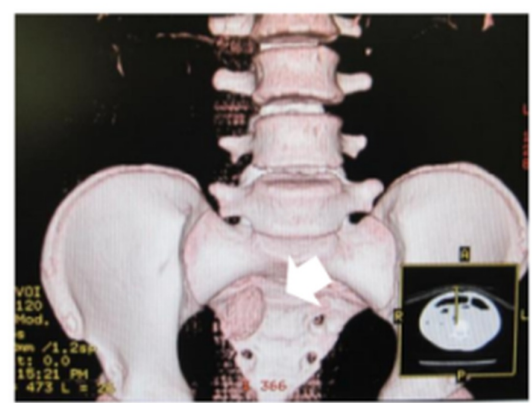

\section{FIGURE 2: Abdominal CT}

A foreign body was detected in the small intestine (arrow). The shape of the object was oval. a: Coronal plain abdominal CT. b: Three-dimensional construction from the CT images.

CT: computed tomography 


\section{Cureus}

Repeated interviews showed the following. The patient had eaten a whole peach eight days before visiting the hospital. Therefore, we diagnosed him with a small bowel obstruction caused by a seed. The foreign object was not expected to be discharged naturally because of its size. Therefore, we decided to perform surgical treatment. Intraoperatively, the foreign body was found impacted at the small intestine (approximately $20 \mathrm{~cm}$ from the oral side of the terminal ileum) (Figure 3).

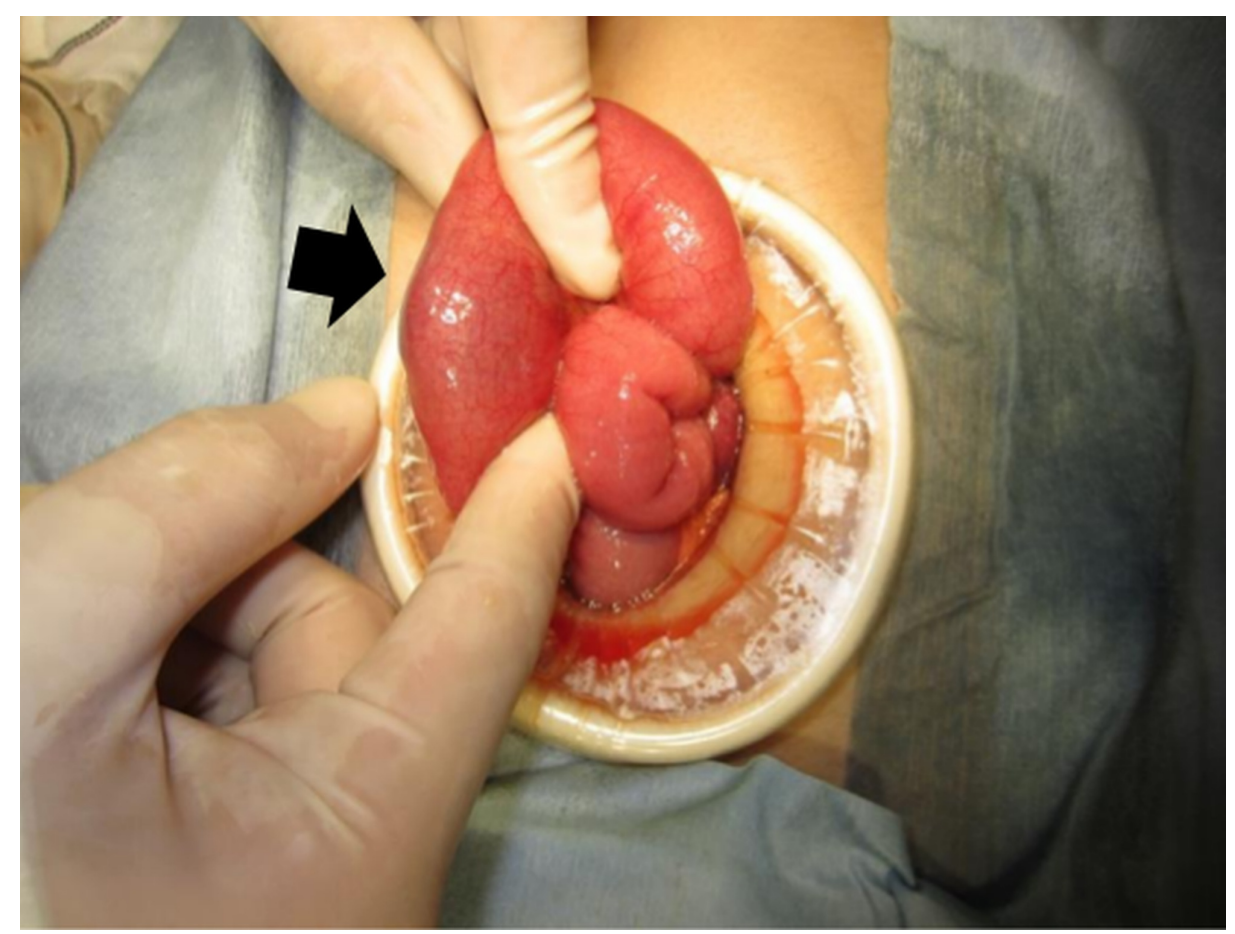

\section{FIGURE 3: Operative findings}

The foreign body (arrow) was found impacted at the small intestine (approximately $20 \mathrm{~cm}$ from the oral side of the terminal ileum). Enterotomy was performed and the object was manipulated out of the small intestine.

There was no major damage and no defects in the neighboring small intestine. Furthermore, there was no gastrointestinal disease in any other site of the small intestine. Enterotomy was performed proximally and the seed was manipulated out of the small intestine. The bowel condition was good (no damage or stenosis), and primary repair of the enterotomy site was performed. The diameter of the foreign body was $35 \times 28 \mathrm{~mm}$, and it was a peach seed, as expected (Figure 4). 


\section{Cureus}

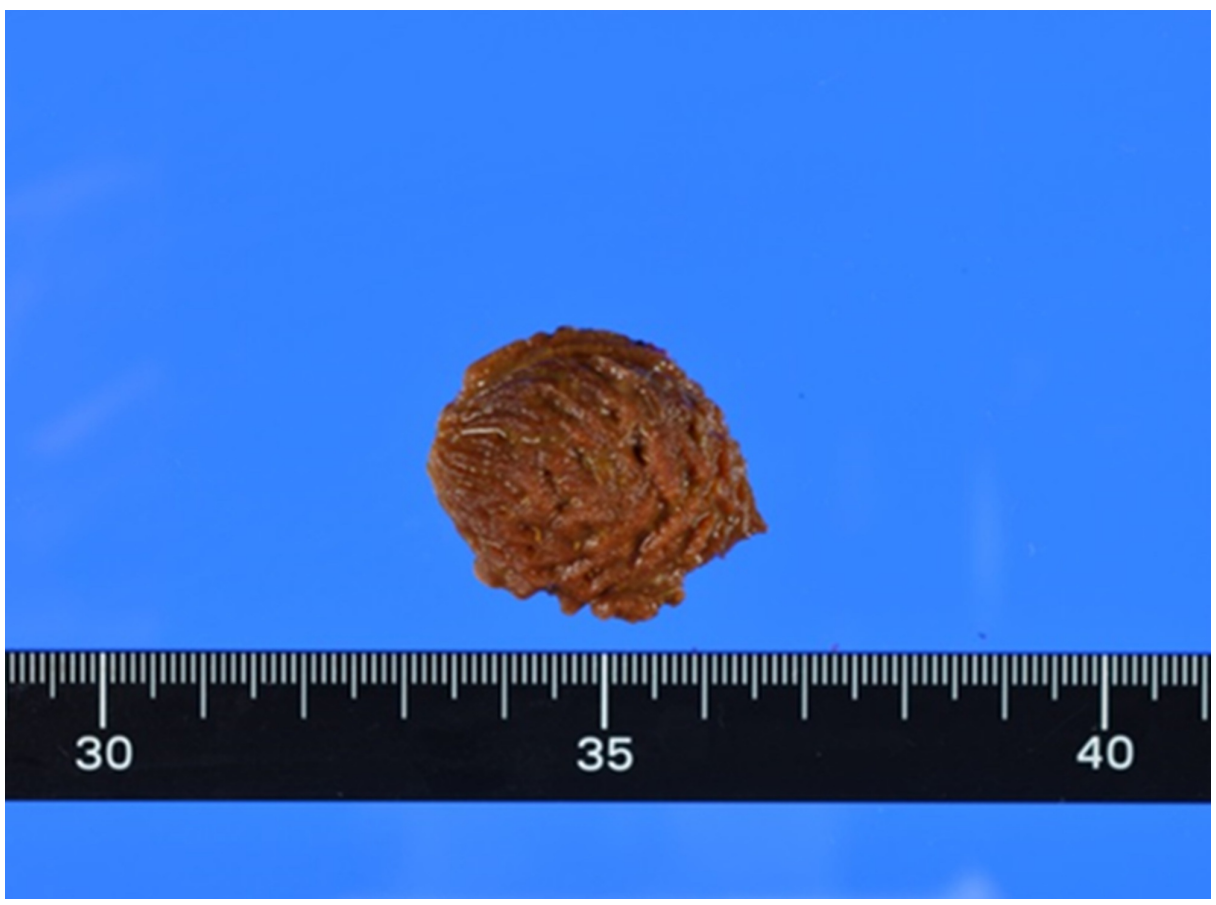

\section{FIGURE 4: Foreign body}

Macroscopic examination of the foreign body. The foreign body was a peach seed and the size of the seed was $35 \times 28 \mathrm{~mm}$.

The patient was discharged nine days after surgical treatment, with no perioperative complications.

\section{Discussion}

Intestinal obstruction caused by plant seeds (IOPS) is rare because the shape of plant seeds is oval, and their size is small. There have been only four previous reports on IOPS [4-7]. Plant seeds sometimes form bezoars, but IOPS is a different disease from intestinal obstruction caused by bezoars in the clinical setting. Intestinal obstruction caused by bezoars has been reported [8]. However, bezoars can be formed from various objects (e.g., hair, fiber-rich vegetables) [9]. We found more reports on IOPS in Japan than in Europe and the United States. The reason for this finding could be due to differences in eating habits (e.g., Japanese people often eat Ume). We reviewed 29 reported cases of IOPS in Japan (Table 2; one English report and 28 Japanese reports). 


\section{Cureus}

\begin{tabular}{|c|c|c|c|}
\hline Number of cases & & \multicolumn{2}{|l|}{29 (Male: 12, Female:17) } \\
\hline Age & & \multicolumn{2}{|l|}{ median 77.5 (range 15-91) } \\
\hline \multirow{5}{*}{ Type of plant } & & Japanese apricot (Ume) & 19 \\
\hline & & Loquat & 4 \\
\hline & & Bayberry & 1 \\
\hline & & Persimmon & 3 \\
\hline & & Peach & 2 \\
\hline \multirow{4}{*}{ Site of obstruction } & & lleum & 18 \\
\hline & & Colon (right-side) & 3 \\
\hline & & Colon (left-sıde) & $r$ \\
\hline & & Rectum & 1 \\
\hline \multirow{9}{*}{ Based gastrointestinal disease } & \multirow{8}{*}{ Yes } & Post-radiotherapy (RT) & 9 \\
\hline & & Colon cancer & 10 \\
\hline & & Postoperative adhesion & 1 \\
\hline & & Intestinal carcinoid & 1 \\
\hline & & Crohn's disease & 1 \\
\hline & & Anastomotic stenosis & 2 \\
\hline & & Ischemic colitis & 1 \\
\hline & & Intestinal Tb & 2 \\
\hline & \multicolumn{2}{|l|}{ No } & 2 \\
\hline
\end{tabular}

TABLE 2: Review of reported cases of intestinal obstruction by plant seeds in the Japanese literature

Importantly, 93.1\% (27/29) of these patients had gastrointestinal disease in the site of the obstructed intestine. Only two cases without gastrointestinal disease were reported, including the current case [7]. In the healthy gastrointestinal tract, there can be four sites of obstruction: cardia, pylorus, ileocecal valve, and anus. The majority of foreign bodies that pass through the pylorus can be discharged to the outside from the anus naturally [2-3]. As described above, swallowed plant seeds are expected to be discharged naturally more often than other foreign bodies. The ileocecal valve of the young will be narrower than that of adults. This may be one of the reasons why the seed stagnated in the small intestine in our case.

Preoperative diagnosis of IOPS is not difficult because CT findings are characteristic of high density outside and low or iso-density inside the object. Therefore, when IOPS is diagnosed, we should consider that there may be gastrointestinal disease in the intestine.

\section{Conclusions}

We report a rare case of IOPS without gastrointestinal disease. We wish to emphasize that IOPS without gastrointestinal disease is rare, but detailed interviews at a medical examination can identify this condition.

\section{Additional Information}

\section{Disclosures}

Human subjects: Consent was obtained by all participants in this study. Conflicts of interest: In compliance with the ICMJE uniform disclosure form, all authors declare the following: Payment/services info: All authors have declared that no financial support was received from any organization for the submitted work. Financial relationships: All authors have declared that they have no financial relationships at present or within the previous three years with any organizations that might have an interest in the submitted work. Other relationships: All authors have declared that there are no other 


\section{Cureus}

relationships or activities that could appear to have influenced the submitted work.

\section{References}

1. Samdani T, Singhal T, Balakrishnan S, Hussain A, Grandy-Smith S, El-Hasani S: An apricot story: view through a keyhole. World J Emerg Surg. 2007, 2:20. 10.1186/1749-7922-2-20

2. Gumus M, Kapan M, Onder A, Yagmur Y: An unusual cause of small bowel obstruction; dried apricots. J Pak Med Assoc. 2011, 61:1130-1131.

3. Durian seed masquerading as gallstone ileus on computed tomography . (2010). Accessed: December 21, 2018: http://www.annals.edu.sg/pdf/39VolNo9Sep2010/V39N9p745.pdf.

4. Khanna SK, Agnone FA, Leibowitz AI, O’Donnell JE: Early diagnosis of colon cancer due to Citrullus vulgaris. Gastrointest Endosc. 1992, 38:734-735. 10.1016/S0016-5107(92)70591-4

5. Faircloth DE, Robison WJ: Obstruction of the sigmoid colon by grape seeds . JAMA. 1981, 246:2430. 10.1001/jama.1981.03320210012007

6. George AJ, Fallaize RC, Bennett J, Shabbir J: Ileostomy obstruction by ingested apricot stone with clinicalradiological-pathological correlation. BMJ Case Rep. 2015, 10:bcr2015210594. 10.1136/bcr-2015-210594

7. Sato S, Maekawa T, Sato K, et al.: A successfully treated case of small bowel obstruction caused by the seed of a Japanese apricot, and leading to acute renal failure. JJCS. 2005, 4:671-674. 10.4030/jics1979.30.4 671

8. Dikicier E: Intestinal obstruction due to phytobezoars: an update . World J Clin Cases. 2015, 3:721-726. 10.12998/wjcc.v3.i8.721

9. Wang P-Y, Wang X, Zhang L, Li H-F, Chen L, Wang X, Wang B: Bezoar-induced small bowel obstruction: Clinical characteristics and diagnostic value of multi-slice spiral computed tomography. World J Gastroenterol. 2015, 21:9774-9784. 10.3748/wjg.v21.i33.9774 